\title{
LA POETTICA DEL FUTURO DE LUIS CERNUDA Y SU REFLEJO EN FRANCISCO BRINES
}

\author{
Mark C. Aldrich \\ Dickinson College. Carlisle. Pensilvania. Estados Unidos.
}

\section{I.-INTRODUCCIÓN: EL FUTURO Y LA CRITICA CONTEXTURAL.}

Una de las bases esenciales de la poesía de Luis Cernuda es el futuro, tanto como posibilidad de salvación como única vía hacia el reconocimiento y el diálogo. Se relaciona íntimamente, por supuesto, con el deseo, puesto que todo deseo es, de cierta manera, una mirada hacia el porvenir. Este ensayo propone acercarse al papel fundamental del futuro en la obra de Cernuda y el legado de éste en una obra de Francisco Brines. Se comentarán, brevemente, dos obras surgidas de la experiencia mexicana de Cernuda, Variaciones sobre tema mexicano y Poemas para un cuerpo, para luego pasar a una consideración de la relación entre éste y Poemas a D. K. de Brines.

Para Cernuda, tan consciente de, y sensible a, la poca, y muchas veces negativa, atención, que su obra provocó durante su vida, el futuro representaba una esperanza con la cual seguir creando versos. Ya en el año 1942 afirma a su amiga Nieves de Madariaga: Si hay destino envidiable para un poeta es hallar camino hacia las gentes que vivan después de él, a través de la ceguera de los contemporáneos" (Valender, 9). Dos años más tarde, escribió a su amigo Gregorio Prieto que, me alegra tanto ver que es la gente joven quien empieza a comprender y a amar mi trabajo, entre la indiferencia de las gentes de mi generación y la ignorancia de las gentes de la generación anterior" (Valender, 16). En Como quien espera el alba, de 1943, aparece el conocido 
A un poeta futuro," donde envisiona, como si de un amigo ya conocido se tratara, al poeta futuro leyendo sus versos:

Cuando en días venideros, libre el hombre

Del mundo primitivo a que hemos vuelto

De tinieblas y de horror, lleve el destino

Tu mano hacia el volumen donde yazcan

Olvidados mis versos, y lo abras,

Yo sé que sentirás mi voz llegarte,

No de la letra vieja, mas del fondo

Vivo en tu entraña, con afán sin nombre

Que tú dominarás. Escúchame y comprende (212).

La insistencia con la cual Cernuda huye de un presente de incomprensión hacia un futuro de reconocimiento y comuncicación verdadera (pero sin olvidar el importantísimo recurrir al pasado también), ha sido uno de los puntos de apoyo fundamentales de la unidad de su obra. Este gran sentido de unidad está centrado en el yo" poético que es el eje de su cosmovisión. Ya en 1959 el poeta mexicano Tomás Segovia dijo que, Luis Cernuda ha sido uno de los casos más claros de voz poética. Lo que ha habido siempre en su mejor poesía ha sido eso: voz..." (Valender, 38). Más que la de cualquier otro poeta de la generación del '27, y posiblemente más que la de cualquier otro poeta importante del siglo veinte, esta voz poética se presta a una lectura hecha en clave biográfica. Cernuda mismo dijo, al observar su gran afecto por Poemas para un cuerpo, que esa predilección invitaba la crítica de que no sabja 'mantener la distancia entre el hombre que sufre y el poeta que crea" (Historial de un libro, 419). Es decir, la obra lírica cernudiana viene a ser, en palabras de Derek Harris, una 'autobiografía poética" unitaria y 'orgánica". (P.?) Se podría decir, incluso, que su poesía abarca un sólo tema, Luis Cernuda; o, mejor dicho, las preocupaciones vitales de éste, que encuentran su expresión más escueta en el título que el poeta dio al conjunto de su obra lírica: La realidad y el deseo.

Sin embargo, la voz de Cernuda es también una voz en diálogo, en diálogo con el otro. Y el otro es otro poeta, un poeta que es tanto todos los poetas del pasado, presente y futuro, así como Cernuda mismo. Otro poeta mexicano, José Emilio Pacheco, dijo de Cernuda que "en la poesía ha cifrado su destino" (Valender, 48). A pesar de la inmensa extensión de la bibliografía crítica sobre Cernuda, sería diffcil encontrar interpretaciones que nieguen esta idea básica del carácter unitario de la obra del poeta sevillano. 
Una consecuencia lógica de esta tendencia interpretativa es la de considerar cualquier poema o grupo de poemas de La realidad y el deseo como partes más o menos representativas del conjunto. Por ejemplo, Jenaro Talens, afirma de La realidad y el deseo que, salvo tal vez la serie de Poemas para un cuerpo, que de un modo u otro conlleva una cierta ordenación interna, el resto de los apartados son colecciones de poemas, más que libros en sí" (55). Richard Curry afirma la cohesive continuity" de la obra cernudiana porque, the contextural continuity prevails over the independence of individual designations within the individual texts that make up La realidad y el deseo (114).

Quizás por eso, relativamente poca atención se ha dado a algunas de las colecciones individuales de Cernuda. Esto no quiere decir, por supuesto, que haya etapas o colecciones de su obra poética sin recibir atención crítica significativa, sino que algunas colecciones, en cuanto obras individuales e independientes no se han estudiado desde esa perspectiva concreta del libro de poesía como tal. Neil Fraistat llama esta atención especial al libro de poesía, en oposición al poema individual o grupos de poemas seleccionados por el crítico por el motivo que sea, crítica contextural. Fraistat observa que, "A contexture might thus be seen as the poem' that is the book itself" (3). Desde esta perspectiva, las circunstancias particulares de la creación y publicación del libro cobran interés particular. Para tener una comprensión de este poema mayor que es el libro, hay una serie de preguntas requisitas. Primero, ¿cuáles podrían ser los motivos, más allá de los meramente cronológicos, de reunir ciertos poemas en colecciones de determinada extensión y carácter particular? ¿Cómo afecta a la lectura de cualquier poema individual el orden y disposición de los otros poemas de la colección? Y al revés: ¿cómo afecta a la lectura del conjunto el efecto específico de un poema en particular? ¿Cuál es el efecto en el lector de la secuencia de los poemas? Finalmente, ¿̨uál es la función de los títulos, tanto de los poemas individuales así como del volumen entero? $\mathrm{Al}$ ir respondiendo a estas preguntas, aparece ante el lector una visión más profunda de la relación tanto entre un poema y otros, así como entre la obra y el poeta.

Dentro de la crítica cernudiana no deja de sorprender una aparente contradicción, o al menos confusión, respecto al sentido de la unidad de su obra. Por un lado, se afirma tal unidad como si fuera la cosa más evidente del mundo. Por otro lado, la base de dicha unidad casi siempre se relaciona con el carácter autobiográfico de la obra. La cuestión es ésta: si la naturaleza de la experiencia humana se supone esencialmente dinámica ( $\mathrm{y}$ en el caso de Cernuda, hay razones de sobra para creerla así), ¿cómo surge de este dina- 
nismo un significado unitario? El sentido común podría llevar a la conclusión de que la unidad pretendida es imposible, puesto que de algo tan sumamente complejo como puede ser la vida humana no es razonable pensar que se pudiera expresar verbalmente con mucho sentido de unidad. Una respuesta sería que el mero hecho de que esta poesía es autobiográfica confiere a la obra su unidad, pero esa respuesta resulta claramente deficiente porque implica que toda obra autobiográfica ( $\mathrm{y}$ hay, acaso, poesía lírica que no sea, en el fondo, autobiográfica?) es de por sí unitaria. Simplemente, hay que matizar que la unidad de $\mathrm{La}$ realidad y el deseo es una unidad dinámica y creada desde sí misma. Con ocasión de la publicación de la tercera edición de La realidad y el deseo, Octavio Paz observó en Claridades literarias que:

Es tal el número de poemas nuevos y éstos arrojan una luz tan reveladora sobre los antiguos, que sólo hasta ahora, cuando podemos contemplarla en su totalidad, comenzamos a vislumbrar el significado de su obra. Como el viajero que ve dibujarse poco a poco, a medida que se aproxima a la costa, la verdadera forma de una tierra desconocida, en el espacio de los últimos veinticinco años nuestra generación ha asistido a la paulatina revelación de un continente poético. (Valender, 21)

Es decir, el significado único que se sostiene sobre la base de una vida con sendas cualidades evolutivas tendrá que entenderse en términos de una unidad lograda al final de una trayectoria vital y no en términos de una unidad apriorísticamente supuesta. Es innegable que la experiencia mexicana de Cernuda ejerció un papel fundamental en este logro. De esta manera, resulta imprescindible meditar sobre el papel de esta etapa de su trayectoria poética.

\section{II.-EL DESEO LOGRADO.}

Cernuda empezó a escribir Variaciones sobre tema mexicano en el invierno de 1950, después de visitar México por primera vez en el verano de 1949. En una carta del 25 de febrero, le escribe a José Luis Cano que:

Entre tanto estoy escribiendo unos trozos en prosa, con algún poema también, donde trato de fijar mi imagen o visión de México. Sería una colección muy breve, con el título, quizá de Concerniente a México. Veremos cómo resulta. Por lo menos me ayuda ese trabajo a la espera del verano y la vuelta a México. $Y$ a poner cariño en algo, que también es cosa que ayuda no poco" (84). 
Esta primera mención de la obra nos ayuda a establecer el particular contexto en que se creó. Se ve que Cernuda empezó con una intención muy clara, la de salvar en el papel su imagen de México. También tiene claro que será una obra corta, un detalle interesante, puesto que en otra carta a Cano, ésta del 17 de noviembre de 1950, Cernuda le escribe que habla terminado ya la obra y que, ya sabes que tengo antipatía a los libros de formato menor" (90). A la luz de este comentario, se puede deducir que la colección le debía de ser muy importante, puesto que a pesar de esa antipatía el libro se llegó a publicar. En la misma carta Cernuda le avisa a Cano que el volumen incluye cosas que no podríais publicar," y que por eso no se lo ofrece para Adonais. La obra se publicó en 1953 en México.

Variaciones sobre tema mexicano consta de treinta y un poemas en prosa. El primero, El tema, "es previo a la página de título y hace el papel de prólogo y el último, Recapitulando," hace el papel de epílogo. Cada una de las veintinueve escenas" o esbozos" que van enmarcados por estos límites es muy breve, de entre una a una y media páginas en extensión. Esta obra corta, una de dos colecciones de poesía en prosa de Cernuda, la otra siendo la preciosa Ocnos, tiene poco de las impresiones de un viajero y por eso se ve que cuando Cernuda le dijo a Cano que quería fijar su imagen" de México se refería más bien a una imagen emocional e íntima y no lo que uno esperaría de una literatura con una mayor carga costumbrista. Como ha observado Luis Miguel Vicente, al comparar Variaciones sobre tema mexicano con Cornucopias de México de José Moreno Villa, Cernuda adapta la experiencia mexicana a los hilos más esenciales de su poesía, para obtener una prosa poética exquisita. Esto hace que en Variaciones sobre tema mexicano sólo aparezcan aquellos temas susceptibles por su naturaleza de ser poéticos"' (26).

Estos temas son muchos (la historia, el idioma, la pobreza, el ocio", por nombrar algunos), pero tienen un importante punto de unión en la perspectiva comparativa, desde la cual se valora positivamente lo mexicano (asociado con una Andalucía idealizada). Como observó Valender, es esta idea de México como encarnación de un paraíso terrestre andaluz... la que predomina en el libro" (1984, p. 98). Se trata también de una visión de Méjico como metáfora de la indolencia, tan importante en el código homoerótico de esta poesía. Ha observado $\mathrm{R}$. Allen que el ocio, actually appears in Cernuda's poetry (and in other gay literature) as the erotic ideal embodied in the indolent youth" (65). Concluye que, the theme of ocio is really that of languid seductiveness, of the inviting indolence of the beautiful adolescent Adonis" (66). Esto en sí parece estar fuera de toda duda, una vez que el lector esté dis- 
puesto a ser receptivo al particular código homoerótico que informa toda la obra de Cernuda.

Otra de las preocupaciones principales de esta colección es la de la relación entre el tiempo y el lugar y su papel en la fijación de una identidad. Por ejemplo, Centro del hombre," incluye esta reflexión: Por unos días hallaste en aquella tierra tu centro, que las almas tienen también, a su manera, centro en la tierra. El sentimiento de ser un extraño, que durante tiempo atrás te perseguía por los lugares donde viviste, allí callaba, al fin dormido" (140). En La posesión" Cernuda desarrolla explícitamente la relación entre México, como expresión metonímica del mundo entero, y la figura del amado, como si de las dos caras de una moneda se tratara:

Aquella tierra estaba frente a ti, y tu inerme frente a ella. Su atracción era precisamente del orden necesario a tu naturaleza: todo en ella se conformaba a tu deseo. Un instinto de fusión con ella, de absorción en ella, urgían tu ser, tanto más cuanto que la precaria vislumbre sólo te era concedida por


inmateriales?

En un abrazo sentiste tu ser fundirse con aquella tierra; a través de un terso cuerpo oscuro, oscuro como penumbra, terso como fruto, alcanzaste la unión con aquella tierra que lo había creado. Y podrás olvidarlo todo, todo menos ese contacto de la mano sobre un cuerpo, memoria donde parece latir, secreto y profundo, el pulso mismo de la vida (137-38).

Ese cuerpo oscuro" será el sujeto exclusivo de Poemas para un cuerpo, cuyo gran logro es la fijación de la identidad del yo poético a través de la figura del amado. Es indiscutible que esta experiencia amorosa fue de tanta importancia para Cernuda que las pocas alusiones que a ella se encuentran en Variaciones sobre tema mexicano resultaron insuficientes como para satisfacer la necesidad de transformar la experiencia vital en expresión lírica. De la experiencia vital que inspiró los poemas, Cernuda reconoce que fue muy tardía, pero añade que, mas al llamarla tardía debo añadir que jamás en mi juventud me sentí tan joven como en aquellos días en México; cuántos años hablan debido pasar, y venir al otro extremo del mundo, para vivir esos momentos felices" (Historial de un libro," 415).

Esta colección de dieciséis poemas, aunque forma parte de Con las horas contadas, de hecho fue concebida por Cernuda como una obra independiente. En 'Historial de un libro" Cernuda nos dice que en 1951 conocí a X, ocasión de los Poemas para un cuerpo' que entonces comencé a escribir" (La realidad y el deseo, p. 415). Se publicó en 1957, en una edición de sólo 
125 ejemplares, en el editorial malagueño El Dardo. Hay una pequeña nota previa en esta edición que dice lo siguiente: estos dieciséis poemas forman una breve serie independiente, dentro del libro inédito Con las horas contadas (1950-1956), sección X de La realidad y el deseo." Aquí la palabra independiente no es nada casual, pues cifra con claridad el estatus particular de esta obra: el momento y el lugar en la lírica cernudiana donde la realidad y el deseo mejor se congenian.

Me remito, otra vez, a la correspondencia entre Cernuda y Cano, ahora para demostrar la atención que puso aquel en la preparación del volumen. En una carta del 10 de octubre de 1957 se refiere al editor que preparaba el librito, diciendo: me disgustó mucho que me corrigiera la puntuación de todos los poemas, alterándolos tanto de sentido como de ritmo, y me disgustaron más los dibujitos que un señor Alvarez Ortega, por empeño de Bernabé, hizo para los versos. Eran malos casi todos, sin relación alguna con el texto y varios en extremo indecorosos. Querrás creer que se trataba de braguetas.

Pocas veces he sentido humillación y vergüenza mayor. Estoy que no sé que hacer; con la obstinación de mula que tiene Bernabé, ya no puedo decirle que desista de publicar los versos, que es lo que quisiera hacer. (135).

Afortunadamente, el libro se publicó sin los dibujos y con la puntuación original que quería Cernuda. Es poco probable que Cernuda realmente hubiera deseado no ver esta colección publicada independientemente. Lo que sí se nota en esta queja es su orgullo característico y el pavor que seguramente sentía ante la posibilidad de ver su obra convertido en algo frívolo por culpa de los dibujos.

Lo más destacable de la serie es que toda la atención está en la figura del amado y lo que el amado le da al amante. Según Carlos Ruiz Silva, el rasgo más original y cernudiana de esta colección" es la idea de que el amado existe porque el amante lo crea." Opina Ruiz Silva que este rasgo podría resumirse en el último verso del poema IX, De donde vienes'; Un puro conocer te dio la vida, lo cual debe traducirse por: mi conocimiento te dio la vida" (139). Ruiz Silva tiene razón; sin embargo, el amante también se dirige a sí mismo, a ese otro que es el yo' protagonista de La realidad y el deseo. Es decir, la voz poética habla consigo mismo, en celebración del encuentro con el amado. Incluso en el poema III, Para ti, para nadie," en el cual parece que el tú" es claramente la figura del amado Estas líneas escribo,/ únicamente por estar contigo"), la posibilidad de una lectura a base de un autodiálogo" sigue muy vigente. Es en este poema que encontramos los versos y yo, este Luis Cernuda / Incógnito, que dura / Tan sólo un breve espacio "de amor espe- 
ranzado". Al referirse aquí Cernuda a sí mismo por nombre (algo único en su obra), hace una referencia a ese deseo que siempre llevaba dentro: de que su obra le sobreviviera.

\section{III.-EL LEGADO DE CERNUDA EN LA OBRA DE FRANCISCO BRINES.}

En 1986 Francisco Brines juntó veintisiete poemas en un libro titulado Poemas a D.K. La colección consiste casi exclusivamente de poemas previamente publicados, puesto que sólo los últimos tres eran inéditos. Esta publicación no fue recibida como un acontecimiento literario de trascendencia alguna, y de hecho, cualquier atención que recibiera en su momento se eclipsó con la publicación pocos meses después de $\mathrm{El}$ otoño de las rosas, críticamente aclamada y ganador, entre otros premios, del Premio Nacional de Poesía. Sin embargo, Poemas a D.K. no debe quedarse al margen de $\mathrm{El}$ otoño de las rosas porque es una obra de peso propio y representa un homenaje lírico, no sólo al individuo del título, sino también a una influencia principal de Brines, Luis Cernuda. Más especificamente, se verá que el modelo para Poemas a D.K. es Poemas para un cuerpo.

Cuando se hablan de influencias en la poesía de Brines, el nombre de Cernuda surgen inevitablemente, pero nadie ha estudiado hasta ahora esta relación en detalle. José Luis García Martín, por ejemplo, nota que, La influencia de Cernuda ha sido señalada por todos los críticos que se ocuparon del poeta. Quizá más que influencia deba hablarse de afinidad espiritual" (1985, p. 197). Sin embargo, para hablar de manera significativa de esta importante relación poética habrá que ser más específico que referencia a una afinidad espiritual. El propio Brines ha reconocido su deuda literaria a Cernuda y le pone junto a Juan Ramón Jiménez como uno de los poetas principales a quien tiene devoción como lector. Sobre todo, es lo que la obra de Cernuda revela sobre la relación entre el autor y su obra lo que más le ha interesado a Brines. En una entrevista de 1980 aludió a su interés en esta dinámica:

La fuerte presencia de estos dos grandes poetas (se refiere a Kavafis y Cernuda) en la poesía de nuestro tiempo tiene un importante punto de apoyo, aparte de su excelsa calidad y por otras muy importantes características, en el peculiar erotismo que informa sus obras. El hecho de que desvelasen en ellas, con franqueza y verdad inusuales, su condición homosexual, ha ayudado en importante medida, a la estimación obtenida. En cuanto que 
sus poesías son profundamente confesionales, y quieren testimoniar la experiencia profunda de la vida, la franca expresión de un impulso y de unos hábitos totalmente inaceptables para la sociedad de su tiempo. los valoraba, de cara a una minoría cada vez más crecida, como paradigma de una poesía de ruptura. No olvidemos que la homosexualidad ha sido el tabú más inconmovible y escarnecido por la sociedad. Y, probablemente, lo es aún en gran medida. Estos poetas no sólo la defendían, sino que llegaban a la exaltación de la misma, apoyados en la mágica calidad de sus versos. Esta posición significaba un ataque frontal al centro más sensible de la moral convenida, y de ahí la importancia tan relevante de los mismos; se transforman en símbolos de la oposición a una moral históricamente caduca, y, por ello, especialmente injusta (Cuervo, 22-23).

En el caso de mi relación con Cernuda y Kavafis hay posturas vitales cercanas, y creo que, en algunos poemas míos, he aprendido conscientemente de ellos a situar en el texto al hombre que yo soy. (29).

Brines revela aquí un interés en las posibilidades autobiográficas del la poesía, pero es importante no interpretar de manera demasiado literal el significado de 'situar en el texto al hombre que yo soy." Se refiere, al menos en parte, a la naturaleza homoerótica de los poemas de amor, pero esto no quiere decir que su lectura nos da una imagen de espejo del autor. Por ejemplo, Brines ha observado reiteradamente que su poesía no refleja la alegría que hay en su vida real:

En lo que a mi se refiere, los aspectos felices de la vida no son cantadas nunca, o apenas, desde su inmediato goce; asl como los momentos exultantes del amor, o la participación de la alegría, son acontecimientos prestigiosos que, en mi poesía, sólo aparecen desde su pérdida. Esta limitación creadora es tanto más extraña cuando consideramos que ella no se produce en nosotros al ser lectores maravillados de estos mismos acontecimientos en otros poetas $(1984$, p. 31).

Mi lectura de Poemas a D.K. tiene el propósito fundamental de demostrar la importancia de la contextura en la construcción del significado así como su base esencialmente intertextual. Lo que hace Brines con esta pequeña colección es crear un nuevo significado que, al menos para el lector, no existiría sin la reordenación de los poemas hecho por el autor. Esta reordenación es también, en palabras de otro poeta valenciano, Ricardo Defarges, una reflexión crítica sobre la propia creación," que resulta ser de una ineficacia esencial" puesto que nuestra obra no va a existir, y, sobre todo, no va a quedar, más que en los demás" (7). El acto mismo de crear la colección incluye una revaluación de su propia obra, pero, de igual importancia, 
resulta también en un retorno crítico a una de las principales influencias poéticas en Brines, Luis Cernuda. Poemas a D.K. constituye, de parte de Brines, una relectura de Poemas para un cuerpo, así como una manera de resolver su ansiedad" ante la influencia cernudiana.

En más de una ocasión Brines ha descrito su descubrimiento de la poesía de Cernuda en una antología y el impacto que le causó como poeta joven. Fue un descubrimiento que le dejó, en palabras de Brines, enteramente deslumbrado" (303). Hablando de sí mismo en tercera persona, escribió Brines que, Desde entonces, sabiendo tan poco del poeta, le amó, del mismo modo que al músico que le despertara el primer sentimiento de honda melancolía" (1962, p. 152). A partir de entonces perseguía la obra de Cernuda, en aquel entonces de difícil encuentro, hasta que por fin tuvo lugar el feliz encuentro... en un secreto lugar, a ras del suelo, de una pequeña e íntima librería: Abril. El libro: Cómo quien espera el alba (303). Finalmente, nos dice Brines que "Aquel muchacho, al tener conocimiento de esta poesía, se sintió milagrosamente fortalecido. No siempre es posible sorprender, tan vivo, el fervor de los hombres, y emociona profundamente si el descubrimiento tiene lugar en edad tan desvalida y arriscada como la adolescencia. Entonces no es extraño que la alegría y la gratitud se asomen a los ojos, con un brillo de lágrimas" (152-53).

Hay que puntualizar aquí que es en esta colección, Como quien espera el alba, donde se encuentra el muy conocido poema "A un poeta futuro," ya citado arriba, que prevee la situación exacta que Brines recuerda con tanta emoción. Este agradecimiento se hizo manifiesto en 1962 cuando Brines colaboró, junto a José Angel Valente, Jaime Gil de Biedma entre otros, en un homenaje especial a Cernuda publicado por La caña gris, una revista valenciana de breve duración. Brines contribuyó con un estudio titulado, simplemente, "Ante unas poesías completas". "Sólo hace falta notar aquí que Brines expresa reiteradamente su admiración por la hondura fatal $e$ insobornable" (321) de Cernuda, una referencia codificada, al menos en parte, a la homosexualidad del poeta, la cual Brines expresa como una ética personal": La ética española siempre ha sido colectiva y de raíz tradicional. En la poesía de Cernuda, la ética se nos ofrece como un resultado personal y contraria, muy a menudo, a la que sustenta tradicionalmente el español. Creemos, no obstante, que esta cualidad independiente ha sido bien considerada por los lectores que, individualmente, han llegado a esa poesía" (136).

Decir que Cernuda es el héroe poético" de Brines quizá no sea exagera. En el estudio de 1962 afirmó que Cernuda es el autor de los poemas de 
más desnuda valentía de nuestra literatura; un una literatura tan presionada por los intereses creados, colectivos o personales, le eleva a la categoría heroica (137). Poco después (1965) Brines expresó su admiración poéticamente en un poema titulado "La mano del poeta (Cernuda)", uno de los pocos poemas de Brines sobre otro poeta. Fue motivado, sin duda, por la muerte de Cernuda en 1963. Brines describe a Cernuda como un héroe estoico:

estabas hecho con el divino fuego de los héroes

Te contemplábamos desde lejos, la lucha desigual, y tú de pie;

la injusticia del hombre, las gigantes pasiones de tu espiritu, $y$ tú de pie;

sosteniendo las piernas con las manos, pero de pie... (Ensayo de una despedida, 100)

Finalmente, es importante observar que mientras Brines avisa que, toda teserva es poca al hablar de influencias," también ve con buenos ojos las comparaciones entre su obra y la de Cernuda: no sólo acepto la posibilidad de deudas literarias con Cernuda..., sino que desearía que las hubiera (Cuervo, p. 28; énfasis mío). Poemas a D.K. es el logro de ese deseo. No me atrevería a afirmar que Poemas a D.K. sean realmente Poemas a L.C.", pero parece evidente que Poemas para un cuerpo son el modelo para el volumen de Brines.

Cualquier discusión de estos poemas debe incluir una consideración de la breve, pero iluminadora introducción," en la cual Brines identifica los orígenes autobiográficos de los poemas que constituyen el libro:

Sabía yo bien que, en la sucesión de mis libros, siempre apareclan ciertos poemas que testimoniaban una concreta experiencia amorosa. Tuvo lugar ésta en los primeros años sesenta, y es en el volumen que incluye tal periodo cronológico,

Palabras a la oscuridad, en donde se encuentra el mayor número de poemas que a ella se refieren. Cuando el libro se publicó ya la historia había concluido (7).

A la luz de una declaración autobiográfica tan manifiesta, parecería difícil discutir este libro sin hacer referencias a su autor. ( $\mathrm{Al}$ mismo tiempo hay que recordar que la poesía hay que entenderla en términos de poesía.) Brines mismo medita sobre la relación entre el poeta y su obra: 


\begin{abstract}
Descubro, una vez más, que el hombre que yo soy, y desde cuya vida se acomete el poema, se ha transformado en este otro, en el protagonista poemático que aquí se muestra con fatalidad al lector. Siempre que ello ocurre el poeta está rozando, con temblor, uno de los más hondos misterios de la poesía. El espejo refleja una imágen que no es otra que la mla, pero es tan sólo ahora cuando la descubro, ya que se me aparece por vez primera, mas al mismo tiempo yo sé que soy también esa otra imágen que el espejo se niega a reflejar (9).
\end{abstract}

Brines reconoce una relación de identidad entre el autor y su obra, pero la encuentra parcial y, por una metáfora del espejo, sugiere que también hay distorsiones. A continuación afirma que el poema, no se identifica con la realidad vivida," pero que puede, sin embargo, desvelarnos un hondo conocimiento, crear una nueva realidad..." Sólo quedan, en palabras de Brines, verdades deficientes" (9). Estas son, al parecer, particularmente deficientes en esta colección por el hecho curioso de que Brines no nos dice nada en la Introducción, y muy poco en los poemas, sobre D.K, el supuesto sujeto.

La incapacidad, o simplemente la negativa, por parte de Brines de describir al amado puede que haga problemática una representación de la realidad, pero en el proceso de la lectura se hace un problema de interpretar la subjetividad. Por ejemplo, Brines emplea frecuentemente el tú" en estos poemas para referirse al amado, D.K., pero en algunas ocasiones ese tú" es un tú/yo" machadiano. Es más, esto se complica debido al deseo del lector de quererse sentir aludido con ese tú."

Estas dificultades se manifiestan claramente en el desarrollo de la colección, que se abre con un poema titulado, significativamente, La sombra rasgada." Aquf, se describe la iniciación del amor, pero un amor ya herido por la sombra del tiempo. El poema termina con estos versos:

Tenía triste el rostro, / y antes que para siempre envejeciera/ puse mis labios en los suyos" (114). El rostro" metanímico que identifica a D.K. se usa por toda la colección y contribuye al gran sentido del carácter esquiva del amor que este libro afirma. El tercer poema, causa del amor," define el amor como una limitada perfección," quizá haciendo eco de la afirmación de Brines de las posibilidades limitadas de la poesía. El poema es significativo también porque es el único en el cual se identifica claramente al amado por nombre. Curiosamente, sin embargo, no se dirige directamente a D.K. Sino a un vosotros," un detalle que llama la atención hacia la naturaleza pretérita de este amor.

Se evidencian otros problemas relacionados a la representación en varios poemas que colocan a los amantes en la Grecia de la antigüedad, 
creando así desdoblamientos fascinantes de la voz poética. Por ejemplo, en el poema Tera" el yo" se imagina en aquella ciudad griega, el sexto siglo antes de Cristo" mientras oye la voz de su amado en las nubes tormentosas que pasan. Este yo" se dirige a un viajero, que es, realmente, él mismo y se da cuenta que de ser la realidad así, podría ver su nombre con el de su amad o grabados en piedra. El poema termina con el acto simbólico de la desposesión de la voz poética: y en el estruendo de su voz/ mi voz arrojo con su nombre dentro" (120).

En la sucesión de los poemas la figura del amado" se va quedando progresivamente en las sombras de la memoria. Raramente es el amor un futuro anhelado, sino casi siempre un pasado en continuo proceso de olvido, y lo que es sólo un anticipo de elegía en el primer poema se convierte rápidamente en una perspectiva explícitamente elegíaca. También, el amado se presenta en términos progresivamente más metafóricos, de manera que en el últimos poema se presencia apenas si es detectable.

Para el lector, esta desenvoltura textual suscita no pocos incógnitos, puesto que los poemas no parecen tener, en una primera lectura, una cualidad claramente narrativa ni tampoco dejan un retrato nítido de la figura del amado. Sin embargo, al ser consciente de la mucha devoción que siente Brines por la poesía de Cernuda, el lector tiene una perspectiva con que leer el volumen que puede enriquecer tremendamente el aprecio del libro como una creación realmente nueva, y no una mera reordenación de poemas viejos. La similitud entre Poemas a D.K. y Poemas para un cuerpo es notable, pero antes de seguir con una comparación textual, hay que identificar brevemente algunos detalles biográficos que ayudan a apreciar mejor la relación entre los dos textos.

Muchos críticos han observado similitudes entre los dos poetas, pero no se ha hecho el esfuerzo todavía de intentar identificarlas con detalle. Puede que sea así precisamente porque lo fundamental de su relación literaria se basa no tanto en similitudes como en una diferencia esencial. En Poemas para un cuerpo, hay una falta casi total de imágenes de calor. El amor y el deseo casi nunca se expresan en términos de fuego, calor o luz, a pesar de la pasión evidente presente en muchos de los poemas. La presencia reiterada de estas metáforas en Poemas a D.K. representan, creo, una función correctiva en la lectura de Brines. En sólo dos ocasiones en los poemas de Cernuda se compara el amor a la luz, y en ambas la comparación va acompañada de oscuridad o sombras. En "Viviendo sueños" el amante contempla al amado: Oscura como la lluvia/ Es tu presencia, y tus oídos / Aunque dan 
luz, es oscura" (25). El poema La vida" termina con una comparación directa entre el amado y el sol:

...tú te pones/ Lo mismo que el sol, y crecen/ En torno mío las sombras/ De soledad, vejez, muerte" (31). Por otro lado, el amado de Brines tiene 'ardientes ojos," existente luz," y la pasión se describe como cuerpos llameando" y cuerpos ardientes." Al final, la postura eleglaca de Brines acaba ofreciendo la misma visión trágica del amor que se encuentra en Cernuda, pero es un amor menos cerebral y la continua búsqueda de nuevas metáforas, que termina en una nostalgia por la inocencia infantil, resulta en una obra menos hermética que Poemas para un cuerpo.

Las observaciones presentadas aquí sugieren que Brines realmente respondió a "A un poeta futuro" de Cernuda. El afán sin nombre" por fin encuentra un nombre en Poemas a D.K. En su artículo en La caña gris, Brines observa que $\mathrm{El}$ poeta sólo tiene un lector con quien debe sentirse obligado, y ese único y primer lector es él mismo" (128). Esa obligación se puede ver aquí como un reconocimiento de una deuda literaria. 


\section{OBRAS CITADAS}

ALLEN, RUPERT C. "Luis Cernuda: Poet of Gay Protest."Hispanófila 83 (1985): 61-78.

BRINES, FRANCISCO. Poemas a D.K. Sevilla: Renacimiento, 1986.

- El otoño de las rosas. Sevilla: Renacimiento, 1986.

- Selección propia. Madrid: Cátedra, 1984.

- Ante unas poesias completeas. La caña gris. Valencia: 1962

CANO, JOSÉ LUIS, ed. Epistolario del '27: cartas inéditas de Jorge Guillen, Luis Cernuda, Emilio Prados. Madrid: Versal, 1992.

CERNUDA, LUIS. La realidad y el deseo (1924-1962). Madrid: Alianza, 1991.

- Poemas para un cuerpo. Málaga: El Dardo, 1957.

CUERVO. (Número homenaje a Francisco Brines.) Valencia: 1980.

CURRY, RICHARD K. Between Platonism and Modernity: The Double Fall' in the Poetry of Luis Cernuda. Jimenez-Fajardo, Salvador, ed. The Word and the Mirror: Critical Essays on the Poetry of Luis Cernuda. Cranbury, NJ: Associated University Presses, 1989.

DEFARGES, RICARDO. Antologia poetica. Barcelona: El Bardo, 1985.

FRAISTAT, NEIL, ed. Poems in their Place. Chapel Hill: U of North Carolina P, 1986/

GARCIA MARTÍN, JOSÉ LUIS. La segunda generación poética de posguerra. Oviedo, 1986.

PAZ, OCTAVIO. Andando el tiempo. Claridades literarias 2, 1959: 23.

RUIZ SILVA, CARLOS. Arte, amor y otras soledades de Luis Cernuda. Madrid: Ediciones de la Torre, 1979.

TALENS, JENARO. "Birds in the Night: ("Lecturas" de Cernuda desde la generacion del 50)." Revista de Occidente 86-87 (1988): 156-65.

- El espacio y la mdscara: introducción a la lectura de Cernuda. Barcelona: Anagrama, 1975.

VALENDER, JAMES, compilador. Luis Cernuda ante la critica mexicana: una antología. México: Fondo de Cultura Económica, 1990.

- Cernuda y el poema en prosa. London: Tamesis, 1984.

VICENTE, LUIS MIGUEL. El tema de Mexico en José Moreno Villa y Luis Cernuda. Mester 16 (2), 1987: 25-34. 